\title{
Morphological Doubling theory to two Bantu Languages Reduplication: A comparative perspective of Kinyarwanda and Swahili
}

\author{
Bazimaziki Gabriel, Bisamaza Emilien, Ndayishimiye Jean Léonard
}

University of Rwanda- College of Education, Department of Humanities and Language Education, P.O Box 55 Rwamagana

\begin{abstract}
Reduplication is a morphological phenomenon which has attracted attention of many researchers in various fields of Linguistics using a number of theories for many languages of the globe. Among other African languages, Kinyarwanda and Swahili have been studied under various approaches each but few comparative studies were conducted on these two Bantu languages spoken in Rwanda and its neighbouring countries of East African region. The aim of this study is to have a look into reduplication- a word formation process, with specific focus on Kinyarwanda and Swahili. Basing on Morphology Doubling Theory (MDT), the researchers examined the similarities and differences between the two languages. Both bounded and unbounded reduplication-full and partial word levels were concerned. Descriptive analysis revealed that the two members of the same set inherently share reduplication features basically complete root, partial and/or syllabic repetition in word formation process.
\end{abstract}

Keywords-Reduplication, base, morphology, verbal extension, MDT, stem, Bantu language.

\section{BACKGROUND AND PROBLEM STATEMENT.}

Every research project starts with an idea; something that the researcher is interested in knowing more about or is worried about; something that is perceived as a problem or as a knowledge gap that needs to be filled (Hewitt, 2009) and reduplication is no exception. Reduplication is a morphological phenomenon which appears in many languages of the world all over the globe. Common morphological process in some languages involves reduplication which marks a grammatical or semantic contrast by repeating all or part of the base to which it applies (O'Grady\& Archibald qtd in Jana, 2000). In many languages, reduplication has held an important place in the area of linguistic studies of morphological features especially form and function of language. The practice of (re-)duplicating words, roots, stems and contrived forms is found in most languages throughout the world - more in some and less in others. Referring to the word Humuhumunukunuku, a state fish in Hawaii, Kauffman (n.d) says that in the world of linguistics, the term reduplication seems in itself to be 'redundantly reiterative,' for duplication is the act of doubling something. The term reduplication, the author goes on to say, derives from the Latin re- 'again' and duplicare 'fold' or 'double'. Thus, he posits that the implication in that case is the act of doubling sounds or entire words. Donka (2002) studied Ablaut reduplication in English and concludes that it is a creative process in which the new structures obey a suite of constraints that are otherwise violated freely in the language. In the same line, McGuckin (2011) presents an account of verbal reduplication in Gapapaiwa, an Oceanic Austronesian language spoken in Papua New Guinea. The author reveals that verbal reduplication in Gapapaiwa involves an interesting variety of phonological patterns like when the verb root kavara 'carry' is reduplicated, it follows the dominant pattern in the language by reduplicating the leftmost metrical foot: kava-kavara. Jana (2000) studied reduplication in Swahili and contended that it is possible to distinguish between partial reduplication (involving a segment or a syllable) and complete reduplication (involving a morpheme). In addition to that, multiple reduplications may occur, allowing three identical elements next to one another. Bantu languages are not exception including Kinyarwanda and Kiswahili, two languages whose speech community include, but is not limited to, a big number of people in East African region. For instance, Kinyarwanda word " gukâambakaamba" (meaning crawl) and Swahili word "katikati" meaning "in the middle" can be fascinating examples to reflect such linguistic aspect. Kinyarwanda and Swahili are studied in isolation and at different levels. However, no single study compares them while they are two largely spoken languages in the Bantu group. As such, this study is an interlanguages comparison that attempts to 
examine the similarities and differences between Kinyarwanda and Kiswahili. The researchers are mainly interested in reduplication in the two languages with particular interest in grammatical reduplication, full word and partial word reduplication, partial stem reduplication. The study comprises of three main parts. The study begins with background of the study by stating the problem while setting the research questions that go along with the research objectives. Part two of the study consists of literature review and part three is concerned with methodology. The next section is concerned with analysis of segments in Swahili and Kinyarwanda and then summary and conclusion.

\section{STUDY OBJECTIVES}

This study hinges on the following objectives:

(i) To identify the role that reduplication holds in Linguistics;

(ii) To describe the common features of reduplication processes in Bantu languages;

(iii) To compare Kinyarwanda and Swahili morphological features.

\section{Study questions and Hypothesis/Assumption}

This study seeks to explore the following questions

(i) What is reduplication and which role does it play in the field of Linguistics?

What are the common characteristics of reduplication processes in Bantu languages?

To what extent are Kinyarwanda and Swahili morphological processes comparable?

From the above research questions, it is important to hypothesize that Kinyarwanda and Swahili agree with doubling in their morphological processes and can be compared under various types of reduplication. As two members of one set namely Bantu Languages, they can both exhibit full word reduplication, full stem reduplication and partial stem reduplication or syllable reduplication.

\section{Study significance}

Any research undertaken aims to benefiting various people including researchers and the community to which data may be deemed useful. This study is no exception. As teachers of Languages in University of Rwanda, College of Education, Department of Humanities and Languages Education, we are aware that this study contributes to the existing knowledge in Linguistic studies and bridges the gap in studies conducted on Kinyarwanda and Swahili under comparative approach. Regarding the study's relevance in education, students doing the combinations that include or related to Kinyarwanda and Swahili languages education will take a three-fold advantage of it. First, they will know more about similarities between the two languages as regard some morphological processes. Second, the study will introduce them, and probably enlighten their further desire, to knowing theories applied in word formation processes. Third, the study will help learners get in touch with the three languages namely Kinyarwanda, Swahili and English as the researchers translated the corpora into English. The study can by and large be a supplement to the existing studies carried out in Bantu languages in particular and descriptive linguistics in general. It is a foundation stone for comparative studies that involve Kinyarwanda and Swahili languages whose speech community is not limited to Rwandans and East Africans but also other parts of the globe.

\section{Theoretical Framework}

This study is a comparison of two Bantu languages as their speech community is, but is not limited to, East African region people. The study is framed on Morphological Doubling Theory. The theory bases on the principles that reduplication is viewed as the double (or multiple) occurrence of a morphological constituent meeting a particular morphosemantic description. Morphological Doubling Theory departs from previous theories in which the reduplicant is treated as an abstract morpheme, RED, whose substance is provided by phonological copying (e.g. Marantz \& Steriade as qtd in Inkelas (2005). In Morphological Doubling Theory, reduplicant and base are both generated by the morphology as part of a construction which also embodies semantic and phonological generalizations about the output of reduplication. The researchers took into consideration the descriptive analysis of the two languages. Thus, comparison was made based on their current functioning regardless of changes that took place or may take place later.

\section{Literature: Reduplication reviewed}

Reduplication has attracted a lot of researchers and most of the discussions on it converge that it is a linguistic form which contains systematic non-recursive repetition of phonological material for morphological or lexical purposes. It is clearly a word formation procedure, to some extent it is not phonologically motivated, in which meaning is expressed by repeating all or part of a word. Reduplication consists of repetition of a sound or syllable in a word, as in the formation of the Latin perfect tetigi from tangere "touch" (Collins English Dictionary, 2017). Studies carried out on reduplication have generated a great deal of interest in terms of understanding a number of properties associated with the word-formation process. Rácová (2013) analyses constraints which apply to the reduplication of verbs as well as the types of verbal reduplication and their functions. The author 
examines reduplication of non-finite verbal forms (the imperfective participle, perfective participle), verbal roots and finite verbal forms in Bengali and concludes that sharing lexical meanings of their simple counterparts they include additional meanings on the content level. Alongside total reduplication (pure and superadded) and partial reduplication, partial reduplication is reduplication where there has not been a reduplication of the whole form of the reduplicant but where there have been phonological changes in the reduplicant. Inkelas \& Downing (2015) cover similar issue and assert that reduplication involves the doubling of some component of a morphological base for some morphological purpose. Unlike other morpheme types, reduplicative morphemes depend for their form on some linguistic property or properties [phonological or morphosemantic properties] of the root, stem, or word, which serves as the base of reduplication. Kim (1997) refers to reduplication as the affixation of a morpheme whose phonological form depends in all or in part on the phonological form of the host stem to which it attaches, to the effect of expressing certain semantic features. $\mathrm{He}$ observes that what is odd about reduplication as an affixation process is the fact that the affixes are phonologically underspecified in reduplication, that is, the reduplicative morpheme is phonologically defective. Elsewhere, Marantz (1982) accounts that except for the fact that the material attached to the stem in reduplication resembles the stem phonologically, reduplication rules look like normal affixation processes. The author concludes that the one unique feature of reduplication, the feature which leads diverse morphological processes to be grouped together under the title reduplication, is the resemblance of the added material to the stem being reduplicated. Lin (2015) examined reduplication in Chengdu, a southwestern Mandarin dialect spoken in Sichuan Province, China. He posits that Chengdu has four common patterns of reduplication, $\mathrm{AA}, \mathrm{ABB}, \mathrm{AAB}$, and $\mathrm{AABB}$ and concluded that stem-internal and - external reduplicants are subject to different alignment constraints, leading to the different reduplicant sizes. Rubino (2005) contends that reduplication is a widely used morphological device in a substantial number of languages spanning in the globe that consists of systematic repetition of phonological material within a word for semantic or grammatical purposes while Niepokuj qtd in Carpio (2000) considers reduplication as a special case of affixation and therefore assumes reduplication to develop in the same way as affixes do, i.e. via grammaticalization of former independent lexical items. She considers full reduplication as equivalent to the composition of two lexical items an idea supported by Bybee,
Perkins and Pagliuca (1994) and then echoed by Huttar and Huttar (1997) that reduplication means the repeating of all or part of a word (more than a single segment), the result still being a phonological word, with its pitch and stress pattern. This is opposed to iteration, the repeating of a word, each word having its independent phonological (and semantic) qualities. Studies on reduplication in Bantu languages won a fertile ground and much was discussed in that area of contention. Odden (1996) explained that Bantu languages have provided a rich empirical domain for investigation in reduplication and the latter often interacts in sometimes unexpected ways with other aspects of the phonology. In Bantu languages, the common word formation processes are affixation (the agglutinative natures of the languages), borrowing (due to contact between Bantu and beyond), compounding (specifically of nouns) and reduplication (Contini-Morava 2007 qtd in Amani, n.d). Hyman (2009) believes that traditional Bantu grammars thus often include sections showing that verbs, nouns, adjectives, numerals and even pronouns and demonstratives can be reduplicated with specific semantic effects. To some extent, Kinyarwanda and Swahili fall in this category. Amani (n.d) put it that reduplication is therefore non-concatenative, and involves copying of either the whole word or part of the word. The reduplicated part of the word could be a prefix or part of the stem or even a suffix and reduplication is either bounded or unbounded (Muhirwe\& Trosterud, 2008). Using Optimality theory, Mecha (2010) focuses on Ekegusii morphological reduplication and contends that little is known on the constraints that determine the shape, the positioning of the reduplicant in relation to the base, the mechanisms of copying and the size of the reduplicated forms in Ekegusii. Framing on Morphological Doubling Theory, Inkelas \& Zoll (2005) found out that reduplication results when the morphology calls twice for a constituent of (mostly) a stem, and then either of these constituents may be further phonologically modified. They conclude that morphological reduplication serves a morphological purpose while phonological reduplication serves a phonological purpose generally entailing a single replicated segment rather than the larger chunks of morphological reduplication. Using some example like umutaabataaba 'type of plant'; kudíigadiiga 'to walk very slowly, akamáarimáari 'gambling' and others, Kimenyi (n.d ) posits that sometimes the same word can appear in a stem reduplication form without affecting the meaning. Referring to examples such as gutuumba 'to swell' 'gututuumba 'to start swelling' kugeenda 'to go'/'walk'kugeendageenda 'to walk around' ukwéezi 'moon/month'icyéezeezí 'moonlight' ubusá (nothing) 'ubusáabusá (very 
little quantity), the same author further postulates that reduplication in Kinyarwanda is both lexical and grammatical. Lexical reduplication, according to him, consists of stems which are already reduplicated while grammatical reduplication affects the stem. In verbs, it is very productive with verbs of movement or sound to show repetition, iterativity or intensity hence concluding that reduplication is done by either repeating the first syllable or the whole stem. However, Kinyarwanda and Swahili reduplication compared have not attracted attention of many researchers. To bridge this gap, we have carried out this study comparing two Bantu languages with special interest in reduplication as phenomenon of copying a part or the whole of the same word. The researchers take into consideration Singha et al. (2016) who believe that reduplication may occur with a prefix, root, stem, suffix in the word or a combination of any of these morphemes; that outcome of reduplication process is to either strengthen or emphasize the original word for grammatical and/or semantic purposes and that the process of reduplication may yield more than one word and yet is considered as a single word from the morphological point of view.

\section{METHODOLOGY}

The design of this study is basically descriptive and mainly qualitative analysis based. The researchers mainly compare the two languages basing on various words used in each. Thus, comparative approach is involved as the two languages are compared at the level of word formation process. The corpuses are the dictionaries and books written in both languages as collected from Library of the University of Rwanda, College of Education. The researchers select the books that may contain reduplicates in both languages. For the most, Synchronic approach serves as a tool in this study. The reason is that "One can approach all different aspects of language, such as grammar, Semantics, Syntax and Phonology etc., from two different points of view such as Diachronic approach which deals with language in its development across time (Moessner, 2001) and synchronic approach which seeks to understand the functioning of language at a single point of time, without reference to earlier or later stages.

\section{Brief description of Kinyarwanda and Swahili}

Kinyarwanda and Swahili are described as two elements of Bantu Languages. Hands (2013) says that Kinyarwanda is "the language most widely spoken in Rwanda," and with the exception of Kiswahili, it is believed "to have the largest group of speakers among the Bantu languages in the region". The author reveals that Kinyarwanda is spoken by
$20,000,000$ people, an estimated 8,000,000 of which reside in Rwanda, Kinyarwanda or other intelligible languages are spoken by over $99 \%$ of the population, often in combination with Rwanda's other official languages, English and French, or the regional language of commerce, Kiswahili. "Mutually intelligible with Kirundi, spoken in neighboring Burundi," Kinyarwanda finds speakers all over Africa's Great Lakes Region in Uganda, Congo, Tanzania, and across Rwanda's Diaspora, more broadly. He asserts that Kinyarwanda is a structurally excellent, if not representative, example of a Bantu language, insofar as it is a tonal language "with the inflection of the voice determining the meaning of words". In addition, nouns found within the language can be divided into a number of classes, made identifiable by their prefixes. Finally, "verbs are modified by prefixes, infixes, and suffixes, and one verb may contain a whole sentence". According to Habyarimana (2006), Kinyarwanda is regarded as the first language for most Rwandans, and an official national language but not everybody is able to conduct a natural conversation in it. The feeling of lack of proficiency in this language leads most Kinyarwanda speakers to mix all the languages they can speak. Kinyarwanda speech community includes members who have acquired this language from different areas and under different circumstances. There is a claim that some have learnt it as their L1 inside the country and in favorable conditions which allow them to feel integrated into their language speech community, while others who were political refugees in foreign countries have acquired it under difficult circumstances, in refugee camps where they were also required to learn other languages for survival, which prevented them from freely using their mother tongue. Rwigamba et al. (1998) posit that the language of Rwanda, called ikinyarwanda, or Kinyarwanda, is a Bantu language of the interlacustrine zone. In the scientific literature, this language is sometimes referred to as rwanda. The authors adds that Kinyarwanda could mean etymologically the thing of Rwanda, the thing that belongs to Rwanda. Since the morpheme -nya- means" belonging to", the meaning is quite close to what J. Dubois and al. (1994:186) call an ethnic adjective, i.e. "an adjective derived from the name of a country or region evoking an affiliation to that country or region (by origin or location. Kinyarwanda means more than just the language since the language refers to the Rwandan culture, the habits and customs of the country. Elsewhere, there are various accounts on how Swahili and Kinyarwanda are not far distant languages. Surabhi (2014) explains well how linguist Malcolm Guthrie, in his research work entitled Comparative Bantu, examined Bantu languages and came up 
with the concept of Proto Bantu which is assumed to be an abstract language from which all the Bantu languages originate. From his research, Swahili is proven to be a Bantu language that shares the same proto language with the other Bantu languages [without excluding Kinyarwanda]. Hence, comparing it with Kinyarwanda is bringing a building stone in the area of studies on African languages, Bantu languages in particular. Habyarimana (2006) accounts that Swahili language dates from the contacts of Arabian traders with the inhabitants of the east coast of Africa over many centuries. Under Arab influence, Swahili originated as a lingua franca used by several closely related Bantu-speaking tribal groups. Swahili is a minority language spoken by less than $3 \%$ of the whole population of Rwanda but won a handful speech community in East African countries neighbouring Rwanda. Some Rwandans learnt it as their first language, namely those who grew up in some parts of Tanzania and of the Democratic Republic of Congo (DRC). People who speak Swahili as their sole mother tongue are usually referred to as Waswahili, but this name refers to their language only and does not denote any particular ethnic or tribal unit. Swahili is widely used as a lingua franca in: (1) Tanzania, where it is the language of administration and primary education; (2) Kenya, where it is, after English, the main language for these purposes; (3) Congo (Kinshasa) [now Democratic Republic of Congo], where a form of Swahili is one of the four languages of administration, the main language for this purpose being French; and (4) Uganda, where the main language is again English. It is mainly found in Muslim communities in which Swahili was introduced for religious and commercial purposes hence a lingua franca language (Surabhi, 2014). Swahili is characteristically Bantu in its grammar, and it has a large vocabulary of word roots traceable to a common Bantu stock. Swahili nouns are divided into classes on the basis of their singular and plural prefixes; prefixes are also used to bring verbs, adjectives, and demonstrative and possessive forms into agreement with the subject of a sentence. Thus, in a sentence with wa-tu, "people" (singular $m$-tu, "person"), and all the words begin with the $w$-/wa-prefix; e.g., wa-tu w-etu wa-le wa-kubwa wamekuja: "those big people of ours have come." Verb stems may be extended by means of varying suffixes, each one with its particular nuance of meaning; e.g., funga ("shut"), fungwa ("be shut"), fungika ("become shut"), fungia ("shut for"), fungisha ("cause to shut"), and so on (Surabhi,2014). Swahili-hub (2014) has it that the most common believed theory that support Swahili as a Bantu language says that Swahili was in existence as a Bantu language even before the coming of the Arabs. The Swahilis people were then known as Wangozi and their language was known as Kingozi. These people interacted with different foreigners though this did not change their language or their identity. This view groups the Swahili with all the other African languages and mostly of Bantu origin . They argue that as much Swahili has a lot of borrowed words from other languages, more so Arabic is not reason enough to disqualify it as a Bantu language. Regarding its morphology, there are a lot of similarities to other Bantu languages. For example, when constructing a syllable just like in all other Bantu languages there are seven structures i.e. (1) Consonant and vowel e.g. dada(sister) (2) Syllables formed from vowels only e.g. oa (marry) (3) Syllables formed from consonants only e.g. mtu (person) (4) Syllables formed from more than one consonants and vowel e.g. ngoja (wait) (5) Syllables formed from a consonant semi vowel and a vowel e.g. mwalimu (teacher) (6) Syllables formed from two consonants a semi vowel and a vowel e.g. mbwa (dog). Bantu languages have nouns that are grouped into different categories known as noun classes. These divisions are based on grammatical agreement in a sentence brought about by subject noun agreement; Swahili has noun classes which also rely on subject noun agreement. Kinyarwanda and Swahili cannot be excluded as they have five vowels (a, e, i, o, u) each just like many other Bantu languages qualifies it to be a Bantu language.

\section{DISCUSSION: KINYARWANDA AND SWAHILI COMPARED}

In this section, different types of reduplication in Kinyarwanda and Swahili are presented. Basing on allomorphs in each of the two cases, the researchers identify some root controlled morphological processes/alliteration be they about complete or whole root reduplication, first syllable, all but first syllable; first syllable lengthened, double reduplication of first two syllables, first two phonemes of first syllable, reduplication of first syllable and of a truncated second syllable, reduplication of first two syllables, with shortening of long vowels in the base. We presented words that are concerned with reduplication in both Kinyarwanda and Swahili languages. Not only nouns and verbs have been the main foci as they are categories that best embody repetition in part or whole of a word stem in the two languages, but also other categories of words have been discussed including adjectives and adverbs. Swahili words are taken from Kamusi Sanifu ya Kiswahili and Standard English Swahili Dictionary. As for Kinyarwanda words, the researchers drew them from Coupez et al. (2005), Coupez (1980) and in other Kinyarwanda books which are currently in use within Kinyarwanda speech community. The words 
are presented as follows: First we list some examples of Swahili words concerning whole stem reduplicated preceded by a prefix (ki-) which is a noun marker. Then we list some of Kinyarwanda nouns of the same kind. Further, Swahili verbs formed by infinitive markers followed by whole stem reduplication are presented. We finally give some Kinyarwanda verbs formed by verb and tense markers followed by the whole root reduplication. Those words are presented as follows:

(1)Full words reduplication in both languages: The similar reduplication in the two languages

Haraka + haraka: harakaharaka/ Mbiyo+ mbiyo: mbiyombiyo (adv.): very quickly $><$ vuba + vuba: vubavuba (very quickly); Pole+ pole: polepole (slowly slowly/ step by step) $><$ buhoro +buhoro: buhorobuhoro (slowly slowly, step by step); Kidogo+kidogo:

Kidogokidogo (little by little) $><$ duke+duke: dukeduke( little by little); Hasa+ hasa: hasa hasa (especially) $><$ Cyane+ cyane: Cyane cyane (especially); Mmoja+ mmoja: mmojammoja (by ones and twos) $><$ umwe+ umwe: umwe umwe (one by one).

As can be seen, the above words reveal that both Kinyarwanda and Swahili languages have fully words reduplicated. Inherently, the above case shows that the meaning of a reduplicated word in one of the two languages is quite the same as the meaning of another reduplicated word in another language and vice - versa as shown by the result of reduplication i.e. meaning after reduplication does not change. For instance, the Swahili word Haraka (quicly) which reduplicates as haraka+ haraka: harakaharaka( very quickly) on the one hand and Kinyarwanda word vuba ( quickly) which doubles vuba+ vuba: vubavuba(very quickly) have quite similar meaning. As shown above, too, hasa+ hasa: hasa hasa (very especially) $><$ cyane+ cyane: cyane cyane (very especially); pole+ pole: polepole (slowly slowly, step by step) $><$ buhoro +buhoro: buhorobuhoro (slowly slowly, step by step) reveal a double similarity between the two languages. Hence, we concluded that this is a leading linguistic similarity between the two languages as regard word formation process with repeated words.

(2) Swahili nouns formed by noun markers such as ki-, vi-, $\mathrm{u}-$, and ma - plus full root reduplicated:
These are words like ki- zungu + zungu: kizunguzungu (dizziness), ki- mbele + mbele: kimbelembele( presumptuousness), ki - wili + wili : kiwiliwili (body ); kitaka+taka: kitakataka (particle of dust). Other Swahili words of this kind include but are not limited to words like mlepelepe/ mtabwatabwa (rice cooked with too much water), umajimaji (being fluid, watery), makolokolo (bag and baggage, utensils), virugurugu/marugurugu (of large size), matubwitubwi/ machugachuga/ chubwichubwi/matubwitubwi, mtambatamba (a braggart). There are other words with full stem reduplication without any prefix such as nungu + nungu = nungunungu (n.) (Porcupine), mbali+ mbali $=$ mbalimbali (adj.) (different, distinct, separate), chepe+ chepe+ chepechepe (adj.) (wet, soapy) taka+ taka+ takataka (n.)(Anything of little value), cheke+ cheke $=$ chekecheke $(\mathrm{n}):.($ siev $)$, chapu+ chapu = chapuchapu (adv., interj.) (Quick, hurry up!). Kinyarwanda has words of this type such as karekare (very early in the morning) resulting from kare (early) + kare; bwoombê bwoombê (very slowly and with attention)

In Swahili, there are words that can also range in the category of full stem reduplication as they consist of a whole part of word that is repeated. These are words like kumbikumbi (white ants in the flying stage), guruguru (a large kind of burrowing lizards), rambirambi (words of condolences) nyatunyatu adv. (teathily), teketeke (weak, feeble) pikipiki (motocycle), kaakaa (the palate of the mouth), katikati (in the middle of)

(2)In Kinyarwanda, nouns of the category of full stem reduplicated words do exist such as:

Ubusâabusâ (a very little quantity of something): U-

busâa+ busâ

uturâakarâaka (The remains of something) : U-tu- râaka+ râaka

amahenêhene/ amashunûshunu, (Goat milk): a- ma-henê + hene/ a-ma-shunû + shunu

rukarakara (adobe): ru- kara+kara

igikârakâra ( a kind of tree): i- ki- kâra + kâra

umurôondorôondo (creeper): : u- mu-rôondo+ rôondo

igicûmucûmu ( a kind of plant): i-ki- cûmu+ cûmu

Umutobôtobo (shrubberry): U-mu- tobô + tobo 
(3) Swahili full verb root reduplication preceded by verb marker include but are not limited to the following words

\begin{tabular}{|l|l|}
\hline \multicolumn{1}{|c|}{ Base } & \multicolumn{1}{c|}{ Reduplication } \\
\hline $\mathrm{Ku}$ - vimba( swell ) & $\mathrm{ku}$-Vimba - vimba: kuvimbavimba( swell progressively) \\
$\mathrm{Ku}$ - cheka (laugh) & $\mathrm{ku}$ - cheka- cheka: kuchekacheka.( giggle) \\
$\mathrm{Ku}$ - randa (dance) & $\mathrm{ku}$ - randa- randa: kurandaranda (dance) \\
$\mathrm{Ku}$ - kimbia (run) & $\mathrm{ku}$ - kimbia- kimbia: kimbiakimbia (run) \\
$\mathrm{Ku}$ - pika (cook) & $\mathrm{ku}$ - pika -pika : kupikapika ( cook) \\
$\mathrm{Ku}$ - chovya (plunge a finger into) & $\mathrm{Ku}$ - chovya: kuchovyachovya ( put into) \\
$\mathrm{Ku}$ - gaa /gala/gara (roll) & $\mathrm{ku}$ - gaa-gaa/gala- gala/gara- gara (roll from side to side) \\
$\mathrm{Ku}$ - maga ( walk) & ku- vuruga: Kuvurugavuruga (mix up by stirring) \\
$\mathrm{Ku}$ - vuruga (mix) & \\
\hline
\end{tabular}

The above data revealed that in both Kinyarwanda and Swahili there are verbs with full base reduplication as their root is entirely copied within their formation process. Vuruga+ vuruga: vurugavuruga (meaning mix up by sitrring) and maga+ maga: magamaga (meaning walk very quickly). Thus, reduplication in this case brings an idea of "again and again" or "doing progressively or continuously" similar to Kinyarwanda verb reduplication as shown in the next point below:

\section{(4)Verb marker Ku- + stem reduplication}

The following are Kinyarwanda words which are of two types. Some words are formed by a prefix (verb tense markers or verb person markers) followed by a fully repeated stem. Another group of these words are either nouns, adjectives and adverbs formed prefix followed by a fully repeated stem such as:

gutoohatooha (bud): ku- tooha + tooha,

kukâbakaba (palpate): ku- kâba+ kaba,

barahâanahaana ( they give each other): ba-ra- hâana+ haana ,

arakâambakaamba ( he is crawling ): a-ra- kâamba+ kaamba guhîirahiira (try vainly) : ku- hîira+ hiira

biragaragara (it is clear): bi- ra-gara+ gara

kuruundaruunda (amass): ku-ruunda+ruunda

vâangavaanga (mix up): ku- vâanga+ vaanga

gukôrakora (touch gently): ku- kôra + kora

gukôondakoonda (walk bending one's head): ku- kôonda+

koonda ; turatîinyatiinya (we hesitate): tu-ra- tîinya+ tiinya

The words as listed above, for both Kinyarwanda and Swahili language, reflect verbal root reduplication. Kinyarwanda verb gutîinyatiinya (hesitate) with the base repeated (-tîinya) and Swahili verb Kurandaranda: (dance about) where the stem - randa is reduplicated and many other related examples revealed that the two languages share this linguistic characteristics as regard morphological processes. It is important to mention that the repeated part/reduplicant may or may not have some related meaning with the reduplication. Kinyarwanda verb gutîinya (fear) and gutîinyatiinya (hesitate) may have some related but not similar meaning. However, verbs such as kuvâanga (blend) kuvâangavaanga (mix by stirring), barahâanahaana (they give each other), gukaanda (feel with one's hand) and gukaandakaanda (to palpate): ku-kaanda + kaanda; kuruunda (amass), and its reduplication kuruundaruunda (pile up,) have identical meaning while the latter is an extension of the former. Another point to mention here is that both languages agree with suffixal reduplication that is conveying the meaning of "again" or "intensification" as in many other languages like Amis, a language spoken in Taiwan.

(5) Syllable reduplicated within the word: Prefixed, infixed and suffixed reduplication

There is another category of Swahili words with stem reduplication which naturally have reduplicated syllables in both Kinyarwanda and Swahili. The reduplicate syllable is either at initial, middle or end position of the word. In the first column, we present words as used in Swahili English Dictionary and in the second column, the words are taken from Coupez et al. (2005) and Coupez (1980). It is important to mention here that the meaning of these words are not carrying the same meaning though compared at the syllabic reduplication level. For the sake of clarification, we presented words from Kinyarwanda language in two columns, for how it is written on the one hand and spoken on the other hand. 


\begin{tabular}{|c|c|c|}
\hline Swahili & \multicolumn{2}{|c|}{ Kinyarwanda } \\
\hline \multirow[b]{2}{*}{ Nyerereza (hide one's action) } & Written & Spoken \\
\hline & Gutatana & Gutâataana (be scartered) \\
\hline Kigeugeu (chameleon/ unreliable person) & Kuririmba & Kurîriimba (sing ) \\
\hline Nyenyelea (get a secret) & Papa & Paapâ (Pop) \\
\hline Sasa (now) & ihoho & Ihoôho (very beautiful girl) \\
\hline Nyerere (brass or copper wire) & kubabara & Kubâbara ( to suffer, get angry) \\
\hline Kutetemeka (be afraid) & kubabarira & Kubâbarira (forgive) \\
\hline Kulalamika( claim) & gusasa & Gusasa (make the bed) \\
\hline Nyenyekevu (humble) & isesengura & Isêsengura (analysis) \\
\hline Kulala (sleep) & agakoko & Agakokô (a small hen) \\
\hline Nyenyekesha (teach humility) & igitutu & Igitûutû (pressure) \\
\hline Baba (father) & akarere & Akarêerê (district) \\
\hline Kaka (grandmother) & Koko & Kokô (surely) \\
\hline Mama (mother) & mama & Maamâ (mother) \\
\hline Barabara (road) & gutata & Gutata (spy) \\
\hline Bubu (deaf and dumb) & ibaba & Ibabâ (feather) \\
\hline Kuku (hen) & inkoko & Inkokô (hen) \\
\hline
\end{tabular}

Syllable reduplication in the above cases shows that in both Kinyarwanda and Swahili, a syllable doubling take place within the stem itself. Kinyarwanda words such as kubâbarira (forgive), Isêseengura (analysis), Gusasa (make the bed) Gutâataana (be scattered), and Swahili words such as kulala (sleep), kutetemeka (be afraid), nyenyekesha (teach humility, nyerere (brass or copper wire), Kulalamika (claim) naturally double one of their syllables either at the initial position or at their end position. The table above revealed that syllable doubling can also be encountered at the level of a disyllabic word as in Swahili words such as mama (mother), kaka (grandmother), baba (father), sasa (now) and many others, a similar feature to Kinyarwanda words such as kokô (sure), maamâ (mother) which are naturally used in a language not stemming from other words. Hence, the two languages have this feature as a meeting points besides being members of the same family.

\section{Swahili and Kinyarwanda compounding}

Compound reduplication takes place in both Kinyarwanda and Swahili languages to show emphasis. In most cases, it is the adjectival ad adverbial reduplication. Some of the words in this category are compounded as Swahili phrases like Vile + vile: Vile vile(as well as) hivyo+ hivyo: hivyo hivyo(so, because), wale+ wale: wale wale( people of that kind) and Kinyarwanda phrases such as: cyane + cyane: cyanecyane(especially), babiri+ babiri: babiribabiri (two by two) bine+ bine: binebine (four by four), bityo+ bityo: bityobityo(as well as), buke+ buke: bukebuke (little by little) among others. This kind of reduplication plays lexicosemantic function putting an emphasis on the word reduplicated. As such, we conclude that this is another similarity between the two languages since both agree with this kind of suffixal reduplication.

\section{SUMMARY AND CONCLUSION}

This study discussed reduplication in Kinyarwanda and Swahili under a comparative perspective. Researchers considered both languages as the members of the Bantu languages and dealt with reduplication at different levels. Morphology Doubling theory (MDT) was worthy in framing and cementing discussion. The two languages were compared at synchronic level and at diachronic level to a lesser extent as the history of both languages was a bit discussed to know about their historical background each. It was demonstrated that Kinyarwanda and Swahili morphological processes agree with various types of reduplication as revealed in analysis. They share the common feature of full word reduplication, full stem reduplication, partial stem reduplication and syllabic reduplication as well. Elsewhere, this study is framed on Morphology doubling theory and involves a synchronic approach or descriptive linguistics. We recommend that further studies be conducted 
using Optimality theory to reduplication in the two languages to bridge the gaps in studies of this kind.

\section{REFERENCES}

[1] Amani Lusekelo (n.d) A description of Kinykyusa reduplication Dar es Salaam: Tanzania

[2] Bybee, Joan, Revere D. Perkins and William Pagliuca (1994). The Evolution of Grammar. Tense, Aspect and Modality in the Languages of the World. Chicago, London: University of Chicago Press.

[3] Carpio, Maria (2000). Description of the types of reduplication in Bikol, a Philippine language. Retrived from $\quad$ http://reduplication.uni graz.at/texte/Dissertation_gesamt.pdf

[4] Collins English Dictionary - Complete \& Unabridged 10th Edition. Retrieved October 18, 2017 from Dictionary.com website http://www.dictionary.com/browse/reduplication

[5] Coupez A., Bizimana S Sematama g., Rwabukumba, G., Ntazinda, C. et Collaborateurs (2005) Inkoranya y'Ikinyarwanda( Kinyarwanda - French). Butare: IRST.

[6] Coupez, A., (1980) Abrégeé de Grammaire Rwanda, T2, Butare, INRS.

[7] Donka, Minkova (2002). Ablaut reduplication in English: the crisscrossing of prosody and verbal art. English Language and Linguistics, 6, pp 133169 doi: 10.1017/S1360674302001077

[8] Donnelly Colleen Elaine (1994) Linguistics for Writers. New York: State University of New York Press.

[9] Habyarimana, H. (2006). Multilingualism and change on the Kinyarwanda sound system post1994.Unpublished master's research report, University of the Witwatersrand, Johannesburg. Retrieved from http://wiredspace.wits.ac.za/bitstream/handle/10539/2 $\underline{123 /}$

[10] Hands, Arthur L. (2013) A Comprehensive Guide to Kinyarwanda. 2nd ed. Berrien Springs: GEM Resources International, Print.

[11] Hewitt, M. (2007) How to search and critically evaluate research literature. The NIHR RDS for the East Midlands / Yorkshire \& the Humber.

[12] Huttar, Mary \& Huttar George (1997) "Reduplication in Ndyuka". In Arthur Spears and Donald Winford (eds.) The Structure and Status of Pidgins and Creoles: Including Selected Papers from the Meeting of the Society of Pidgin and Creole Linguistics. Amsterdam: John Benjamins, 495-414.
[13] Hyman, Larry M. (2009) The natural history of verbstem reduplication in Bantu Morphology, 19(2) available from http://escholarship.org/uc/item/5c26x4k4

[14] Inkelas Sharon \& Zoll Cheryl (2005) Reduplication: Doubling in morphology. Cambridge Studies in Linguistics 106. Cambridge: Cambridge University Press,

[15] Inkelas, Sharon and Downing Laura J. (2015) What is reduplication? Typology and analysis Part 1/2: The typology of reduplication. Language and Linguistics Compass. 9(12) Retrieved from http://www.unice.fr/scheer/egg/Lagodekhi16/Inkelas

[16] Inter-territorial Language (Swahili) Committee to the East African Dependencies (2010) A Standard SwahiliEnglish Dictionary. Nairobi: Oxford University Press.

[17] Jana, Novotna (2000) Reduplication in Swahili. AAP 64 (2000): Swahili Forum VII • 57-73

[18] Kennedy Robert (2008) Synchronic and diachronic approaches to reduplicative morphological alternation. Guest Lecture University of Graz.

[19] Kim Jin-Hyung (1997) An Optimality-Theoretic Approach to Reduplication in Korean Ideophones. Language Research, 33(4).

[20] Kimenyi, A. (n.d) Lexical Variation in Kinyarwanda: Grammaticization at work. California State University at Sacramento. Retrieved from http://www.kimenyi.com/lexical-variation.php

[21]Kimenyi, A. (n.d) Kinyarwanda. California State University at Sacramento. Retrieved from http://kimenyi.com/kinyarwanda.php

[22] Kinyarwanda. Madison: National African Language Resource Center. Print.

[23] Lin Hui-shan (2015) Chengdu Reduplication: An Optimality Theoretic Analysis. Language and Linguistics. 16(6) 843-872

[24] Marantz, A. (1982) Re Reduplication. Linguistic Inquiry. The MIT Press 13(3) 435-482 Stable Available from http://www.jstor.org/stable/4178287

[25] McGuckin, Catherine (2011) Gapapaiwa Reduplication: A Phonological Analysis using Optimality Theory. Retrieved from http://www.gial.edu/GIALens/issues.htm

[26] Mecha, Evans (2010) The Phonology and Morphology of Ekegusii Reduplication: An Optimality Theoretic Approach.

[27]Meyer Paul Georg (2005 Synchronic English Linguistics: An Introduction, 3rd ed. Gunter Nar Verlag. 
[28] Muhirwe, Jackson \& Trosterud Trond (2008) Finite state solutions for reduplication in Kinyarwanda language. Proceedings of the IJCNLP-08 Workshop on NLP for Less Privileged Languages, pages 73-80, Hyderabad, India, Asian Federation of Natural Language Processing.

[29] Odden, David (1996) Patterns of Reduplication in Kikerewe. OSU Working Papers in Linguistics 48, 111-149.

[30] Rácová, Anna (2013) Reduplication of verbal forms in Bengali. Asian and African Studies. 22(2).173-207.

[31] Raimy, Eric (2000) The Phonology and Morphology of Reduplication. Berlin: Mouton de Gruyter.Pp.201.

[32] Rwigamba, B., Nkusi, L, Ruzindana Mathias (1998) The Kinyarwanda language: its use and impact in the various media during the period 1990 -1994. A sociolinguistic study. Retrieved from http://jrad.unmict.org/webdrawer/webdrawer.dll/webd rawer/rec/196070/view/

[33] Singha, Ksh. Krishna B., Singha Kh. Dhiren, Purkaystha Bipul Syam (2016) A Morphological Analyzer for Reduplicated Manipuri Adjectives and Adverbs: Applying Compile-Replace. I.J. Information Technology and Computer Science, 2016(2) 32-40 available from http://www.mecs-press.org/

[34] Surabhi-Sinha (Ed.)(2014) Swahili Language in 'Encyclopedia Britannica' (Retrieved from https://www.britannica.com/topic/Swahili-language)

[35] Swahili hub-the home of Swahili -Learning Swahili from the Source (2014) Jifunze Kiswahili kutoka kitovuni. $\quad$ Retrived from http://www.swahilihub.com/JifunzeKiswahili/2424910 -2424910-lnbuj2/index.html. 